\title{
Philosophiques
}

\section{La petite revue de philosophie, vol. 8, no 1 (automne 1986).}

\section{Jacques G. Ruelland}

Volume 14, numéro 2, automne 1987

URI : https://id.erudit.org/iderudit/027027ar

DOI : https://doi.org/10.7202/027027ar

Aller au sommaire du numéro

Éditeur(s)

Société de philosophie du Québec

ISSN

0316-2923 (imprimé)

1492-1391 (numérique)

Découvrir la revue

Citer ce compte rendu

Ruelland, J. G. (1987). Compte rendu de [La petite revue de philosophie, vol. 8, no 1 (automne 1986).] Philosophiques, 14(2), 450-451.

https://doi.org/10.7202/027027ar

Ce document est protégé par la loi sur le droit d'auteur. L'utilisation des services d'Érudit (y compris la reproduction) est assujettie à sa politique d'utilisation que vous pouvez consulter en ligne.

https://apropos.erudit.org/fr/usagers/politique-dutilisation/ 
La petite revue de philosophie, vol. 8, n' 1 (automne 1986).

par Jacques G. Ruelland

Ce numéro de La petite revue de pbilosopbie comprend les travaux d'un groupe de chercheurs de l'UQTR et de l'UQAM sur "l'histoire de la philosophie québécoise " ainsi que des contributions d'éminents historiens de la pensée.

Les textes englobent la période 1840-1879, soit entre les événements de 1837 et la proclamation du thomisme comme doctrine officielle, et portent sur trois thèmes principaux : le libéralisme, le libre-échange et l'influence de certains intellectuels de l'époque : Étienne Parent, T. A. Chandonnet, Marc Sauvalle, Dominique-Ceslas Gonthier, etc.

On ne peut s'empêcher de songer à l'actualité des deux premiers thèmes. Il n'est pas nécessaire de les définir ici, mais il paraît pertinent d'apprendre ce qu'ils représentaient pour les Québécois d'alors. C'est ce que permettent les articles d'André Vidricaire, «Les débuts de l'économie politique et la question du libre-échange» (pp. 23-58) et de Harel Malouin, «Le libéralisme: 1848-1851 » (pp. 59-101). Dès 1840, E. Parent, Dessaulles, Morin et quelques autres endossent la théorie du libre-échange " pour stimuler l'expansion du peuple canadien-français» (p. 58). Mais cette position ne s'inspire pas de la doctrine catholique et sera vivement combattue. Les limites du libéralisme ont toujours été fixées par la liberté que les gouvernements ont octroyée aux citoyens : c'est pourquoi les partisans de l'ultramontanisme du $\mathrm{XIX}^{\mathrm{e}}$ s. ont attaqué cette doctrine par tous les moyens (p. 100).

L'article le plus intéressant de cette revue est celui de Claude-Élisabeth Perreault: «Paul Marc Sauvalle, un journaliste rebelle» (pp. 161-189). Sauvalle (1857-1920) était un journaliste libéral. Il combattait pour la liberté de presse, de parole, de conscience, et prônait la séparation de l'Église et de l'État et l'instruction laïque et obligatoire. Il s'insurgeait contre la dîme des curés et les exemptions de taxes des communautés religieuses. Bref, c'était un 
homme qui voyait juste et loin! Sa vie fut aussi rocambolesque que put l'être celle d'un journaliste au siècle passé. En 1885, il se fixe à Montréal où il travaille notamment pour La Patrie et où il est mêlé à toutes les disputes de l'époque, l'affaire Tardivel, la querelle Fréchette-Chapman, etc. Suite à certains articles publiés par Sauvalle dans le Canada Revue, celui-ci, ainsi que l'Écho des Deux Montagnes, se fera condamner par Mgr Fabre en 1892 (p. 176). «Lire Sauvalle, c'est rencontrer un journaliste engagé, éloquent et opiniâtre », écrit C. E. Perreault. Anticlérical d'abord, Sauvalle était au XIX ${ }^{\mathrm{e}}$ s. le défenseur de la démocratie et du libéralisme au Québec.

Les articles de cette revue parlent de notre histoire. Écrits par des philosophes, ils affichent une méthodologie qui surprend parfois l'historien. Mais cela ne leur ôte aucune valeur - au contraire. Ils expriment un point de vue original sur une partie de notre histoire souvent fort mal connue, et ils éclairent d'une lumière nouvelle des problèmes d'actualité. Les débats sur le libéralisme, le libre-échange, l'école laïque, la liberté d'expression, n'ont rien de neuf : on pouvait au moins s'en douter. Mais de voir comment ils ont été traités par les libéraux, comment ceux-ci se sont heurtés à de multiples difficultés pour faire valoir leurs idées au XIX ${ }^{e}$ s., voilà qui n'est pas enseigné par nos manuels d'histoire. C'est là que réside la valeur de cette revue.

Département de philosophie

Collège Edouard-Montpetit 